\title{
Micromechanics Investigation of Wood Cell Walls under Compression Loading
}

\author{
E. GÜNAY ${ }^{a, *}$ And H. GOLmOHAmmadi ${ }^{b}$ \\ ${ }^{a}$ Gazi University, Engineering Faculty, Mechanical Engineering Department, 06570, Maltepe, Ankara, Turkey \\ ${ }^{b}$ Gazi University, Graduate School of Natural and Applied Sciences, Ankara, Turkey
}

\begin{abstract}
The aim of this study was to detect the determinations of the $3 \mathrm{D}$ cell deformations of pine wood (Pinus sylvestris L.) in micro-scale $(\mu \mathrm{m})$ under mechanical compression loading. The $20 \times 20 \times 50 \mathrm{~mm}^{3}$ sized wood specimens were tested under compressive pressure load through 35-40 $\mathrm{MPa}$ parallel to the grain orientations. The pressure applied samples were divided into three parts, then processed to form smaller cubic pieces and this pieces stained with gold liquid in order to get scanning electron microscopy images $\left(12 \times 12 \times 12 \mathrm{~mm}^{3}\right.$ parts $)$. The deformed cells were photographed in 3D-plane with magnification of $(100 \times),(1500 \times)$ and in the range of 3.0-5.0 kV light voltage under the scanning electron microscope. Unloaded and loaded pine wood specimens were visualized and photographed to observe and examine the contraction or expansion of the cell walls comparatively. Based on the experimentally obtained microstructural permanent deformations of the cell structures, a numerical model had been proposed to explain the complex behaviour of cell structures under compression loading. Using the finite element method and ANSYS code, the permanent deformation ratios of three different pinewood cell models were simulated for 35-40 MPa loading to explain the overall stiffness and strength of the pinewood cells. In this way, by considering the results obtained from scanning electron microscopy measurements and related finite element analysis solutions, permanent deformation of honeycomb type pinewood cells was examined in detail.
\end{abstract}

DOI: 10.12693/APhysPolA.129.459

PACS/topics: 87.85.gp, 87.17.Rt, 83.80.Lz, 68.37.Ps, 02.70.Dh, 87.16.Gj

\section{Introduction}

In literature survey, some studies were found about the elastic properties of earlywood and latewood rings of pine wood studied on the macro- and microscales according to the type of wood materials. The experimental studies found in literature on macroscale were about obtaining the elastic properties of longitudinal and transverse modulus of elasticity, shear modulus, Poisson's ratio affected by micro fibril angle and wood material type [1-5]. In the experimental studies in microscale, the nanosized components of the wood cell wall levels such as crystalline cellulose, amorphous cellulose, hemicellulose, lignin and water had been found to form the elastic properties of cell wall [6-11]. In the literature survey, the elastic constants available for pinewood (Pinus sylvestris L.) material can be summarized as follows:

(i) Shear moduli values were found as $G_{\mathrm{LT}}$ equal to 4.34-0.77 GPa [1] and 5.72 GPa [2],

(ii) $E_{\mathrm{L}}$ was found by compression test parallel to grain angles as 0.058 (Gauge_1) and 0.071 (Gauge_2) [3],

(iii) $E_{\mathrm{L}}$ was found by tensile test as $9.88-1.59 \mathrm{GPa}[1]$ and parallel to grain angles 5.122 (Gauge_1), 6.044 (Gauge_2), perpendicular to grain angles 0.2279 (Gauge_1), 0.23144 (Gauge_2) [3], 4.423 (earlywood)-13.543 GPa (latewood) [4],

\footnotetext{
*corresponding author; e-mail: ezgigunay@gazi.edu.tr
}

(iv) $\nu_{L R}, \nu_{\mathrm{LT}}, \nu_{\mathrm{RT}}, \nu_{\mathrm{TR}}$ are in an order $0.328,0.292$, $0.382,0.362[5]$.

In literature, a study about the influence of moisture, density and microstructure of latewood on its hydroelastic and shrinkage properties was carried out by computational micromechanical analysis. In this study, the elastic properties of cell sublayers have been determined using the unit cell models $[6,7]$. In another study, micromechanical models available in the short fiber composites were used to predict the stiffness of some commercially important natural fiber composite formulations [8]. In the other two studies, the comparison of conventional composite reinforcing fibers was carried out and the Young modulus of natural spruce wood fibers under tensile load was found as $20.8-60.1 \mathrm{GPa}[9,10]$. The elastic moduli values measured by nanoindentation tests for fiber and parenchyma cell wall of bamboo material were $10.4 \pm 1.8$ and $3.4 \pm 1.3$, respectively, by nanoindentation tests [11]. In the literature survey, in all macro- and microstructural studies conducted on wood fibers, the wood cell was initially described as transversely isotropic structure and then the structure of cell wall was remodelled as layered composite material. The researchers have also assumed that the wood microfibril reinforced composite was arranged as the hexagonal array at cross-sectional view. The cell walls of wood fibers were composed of multiple layers with different thicknesses. Each layer had different spiral microfibril angles (MFA) and chemical components. These layers were named as M, P, S1, $\mathrm{S} 2, \mathrm{~S} 3$ and the basic lamellae in S1, S2 and S3 layers were composed of transverse elastic materials. Researchers have assumed that the microfibrils were arranged as the 
hexagonal array at the cross-section view of wood microfibril reinforced composite. S2 cell wall layer was the most important factor determining the mechanical properties of the wood cell wall, having $80 \%$ of the wall thickness. In a study, the thicknesss of S2 cell wall layer was determined as S2 $4.0 \mu \mathrm{m}$ [7].

In this study, experimental and numerical studies were performed in order to determine the average elastic modulus of the Pinus sylvestris L. earlywood cell wall under compression load. Experimental studies were performed in two stages. In the first step, the compression tests were performed on the wood specimens and in the second step, the microscopic examination of the compressed wood material was carried out by scanning electron microscopy (SEM).

In numerical studies the average elastic modulus of the Pinus sylvestris L. earlywood cell wall was modeled and solved by using finite element method with ANSYS code. In the following sections, detailed explanations can be found related to the studies and the results above mentioned.

\section{Microscopic examination of compression wood specimens}

In our experimental phase of the study, wood test samples were quite resistant to the applied pressure until they start to buckle when compression load is applied parallel to the axis of grain angles of the wood specimen. When the load is applied perpendicular to the axis of the grain angles, they showed weak resistance to the compression and fracture started laterally from a remote location to the center of the specimen.
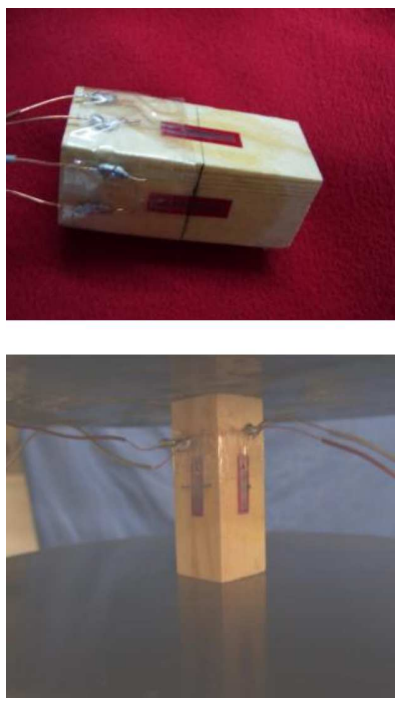

Fig. 1. Pinewood specimen and compression loading on the specimen by the Dartec hydrolic test machine.

In this work, compression tests were performed by Dartec hydrolic test machine (Fig. 1). Compression loading was applied parallel to the grain angles of the wood in room temperature of $25^{\circ} \mathrm{C}$. The moisture content was measured within $5 \%$ levels by Delmhorst Instrument moisture meter. The conducted experimental studies could be described in three stages.

At the first step, the pine wood specimens were prepared in $20 \times 20 \times 50 \mathrm{~mm}^{3}$ rectangular prisms. Then, they were divided into three equidimensional cubic sized specimens and painted with gold liquid in order to obtain SEM images $\left(12 \times 12 \times 12 \mathrm{~mm}^{3}\right)$. 3D cell orientations of the unloaded specimens were viewed and photographed with SEM at $(100 \times)-(1500 \times)$ magnification and the range of light-voltage was $3.0-5.0 \mathrm{kV}$ during the experiment.

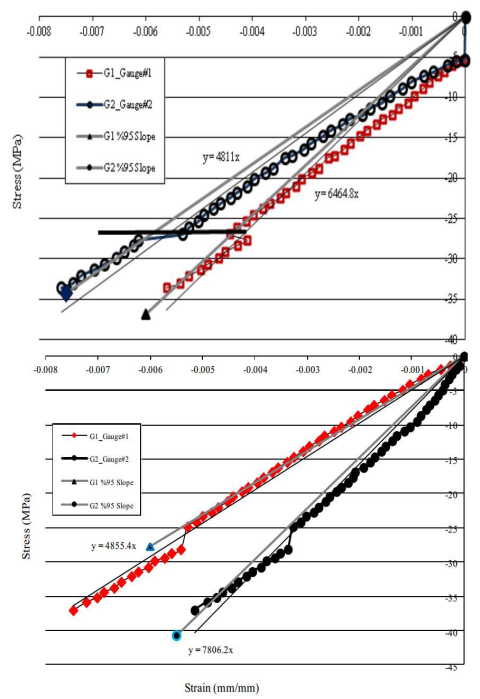

Fig. 2. Stress-strain compression curves: pinewood specimens 9 and 10, loaded parallel to the grain angles.

In the second step, the pine wood specimens were loaded with compression load stress ranges of 0-40 $\mathrm{MPa}$ (Fig. 2).

In the third step, the deformed specimens were viewed with SEM again and sample images were obtained during this procedure. The SEM sample images of the undeformed and deformed cell structures of the wood material were listed in Fig. 3. The average softwood cell dimensions were calculated by using the 80 SEM images. This procedure was determined statistically, by obtaining the averaging data list from the SEM images of unloaded samples and were summarized in Table I as below.

The examined cell structures were formed from sieveplates and the main structural part named as the equivalent cell structure. This equivalent cell model was investigated under the compression loading by isolating the microstructural "equivalent cell structure" part from the whole specimen. Considering the averaging equivalent cell dimensions, finite element solid models were created in three forms: (1) equivalent cell without any sieve-plate, (2) equivalent cell with two sieveplates, (3) equivalent cell with four sieve-plates. By the way, the data obtained from the earlywood cells of the undeformed specimens were gathered by averaging the related cell and sieve-plate dimensions as: (i) cell $\operatorname{height}(\mathrm{ch})=30 \mathrm{\mu m}, \quad$ (ii) $\operatorname{cell} \operatorname{width}(\mathrm{cw})=24 \mathrm{\mu m}$, 
TABLE I

Measured averaging geometrical properties of the unloaded wood cell structures by SEM.

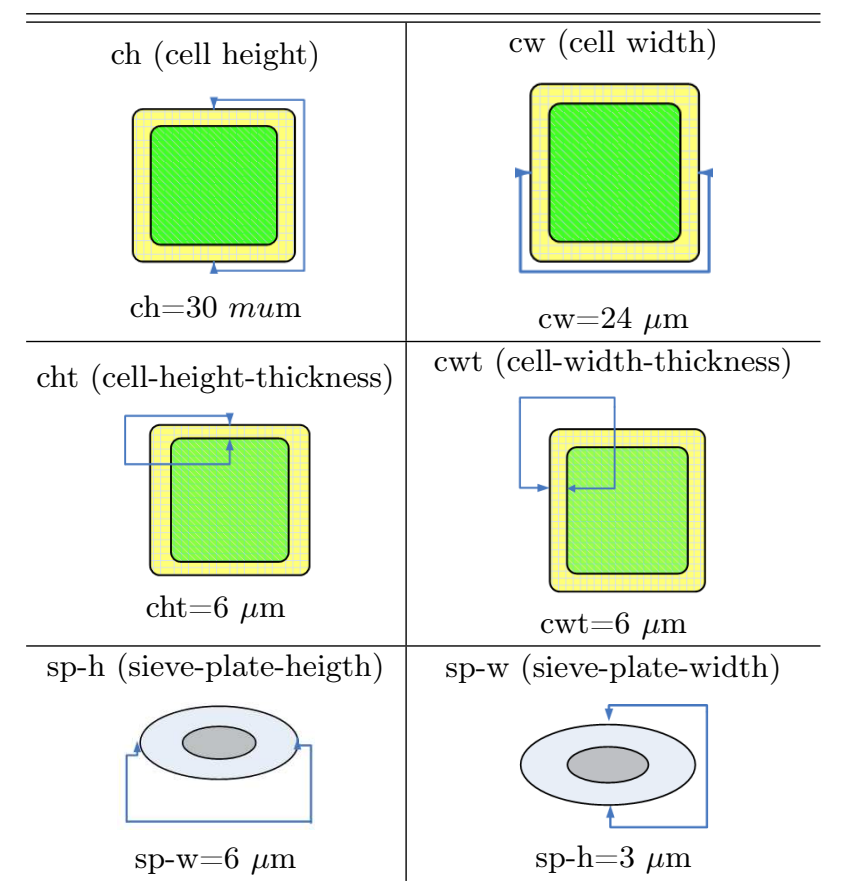

(iii) cell-height-thickness(cht) $=6 \mu \mathrm{m}$, (iv) cell-widththickness(cwt) $=6 \mu \mathrm{m}, \quad$ (v) sieve-plate-heigth(sp$\mathrm{h})=6 \mu \mathrm{m},(\mathrm{vi})$ sieve-plate-width(sp-w) $=3 \mu \mathrm{m}[1]$ (Table I).

\section{Finite element micromechanical modelling of equivalent cell structure}

In order to apply compression loading to the specimen, the bottom of the specimen was fixed and the pressure load was applied to the upper surface of the model. In measuring the strength of the model, three different finite element geometrical cell modeling were generated. The properties of these solid models: (i) model I: equivalent wood cell model without sieveplates, (ii) model II: equivalent wood cell model with two sieve-plates, (iii) model III: equivalent wood cell model with four sieve-plates.

In our study, the finite element analyses solutions obtained by using the ANSYS commercial code. In the modeling stage 3D 20 node structural solid mesh element SOLID186 was used to represent the quadratic displacement behavior. In the solid model simulations the dimensions of the cell were plotted in terms of micrometers $[\mu \mathrm{m}]$. Element nodal degree of freedom was three $\left(U_{x}, U_{y}, U_{z}\right)$. Here, $U_{x}, U_{y}, U_{z}$ were translations parallel to the $x, y$, and $z$ axis, respectively. The numbers of elements and nodes for each generated solid models were as follows: (i) model I has 3272 elements and 6100 nodes, (ii) model II has 120990 elements and 175625 nodes, (iii) model III has 8144 elements and 13724 nodes (Fig. 4).

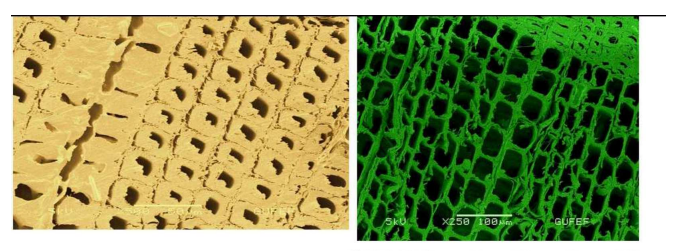

(a) Undeformed configuration of the (b) Undeformed configuration of the cells of pinewood cells under SEM with cells of pinewood cells(latewood, $\times 500$ magnification

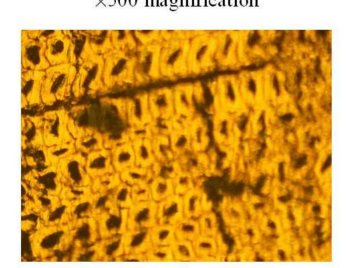
earlywood) under SEM with $\times 500$ magnification

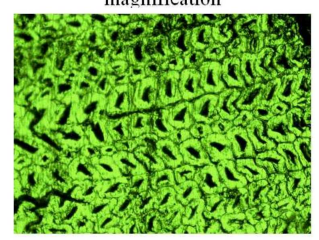

(c) Deformed configuration of the cells of pinewood cells under microscope

with $\times 200$ magnification

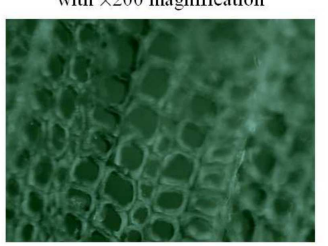

d) Deformed configuration of the cells of pinewood cells under microscope with $\times 200$ magnification

(e) Deformed configuration of the cells of pinewood under microscope with $\times 200$ magnification

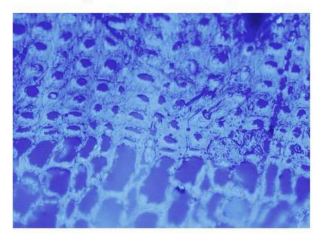

(f) Deformed configuration of the cells of pinewood (latewood, earlywood) under microscope with

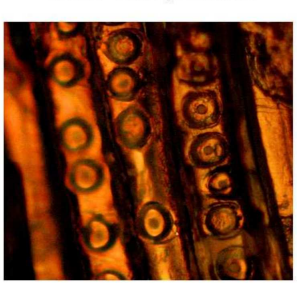

(g) Deformed configuration of the sieve-plates of pinewood under microscope with $\times 200$ magnification microscope with $\times 200$ magnification

Fig. 3. Pinewood (Pinus sylvestris L.) material microscopic views of unloaded and loaded compression specimens.

The compression load was applied to the equivalent cell structure from its front face along the $z$-axis and corresponding maximum strain variations were calculated accordingly. When there were 84 nodal points at the frontal face of the model I and III, the model II had 3585 nodes. Considering the experimental studies, the resultant applied force per cell face was calculated as $3500 \mathrm{~N} / \mathrm{cm}^{2}$. In order to determine the true strength values of cell walls two parameters were selected as variable. The first one was the nodal pressure load and the second one was the elasticity modulus. Variable pressure loading values $P(\mathrm{~N})$ were applied between $6.0 \times 10^{-6} \mathrm{~N}$ and $7.5 \times 10^{-6} \mathrm{~N}$ per node. Material elastic values $\left(\mathrm{N} / \eta \mathrm{m}^{2}\right)$ were changed between 0.08 and 0.2 for the constant Poisson ratio as 0.32 . The maximum developing normal strain along the $z$-axis of the specimen was measured as $0.55 \times 10^{-3} \mathrm{~N}$ (Fig. 2, Fig. 5). Main results were summarized in Table II. 


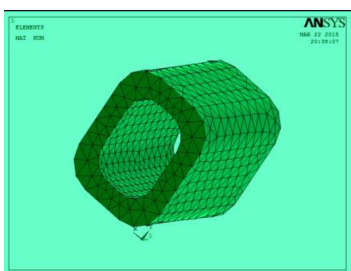

(a)

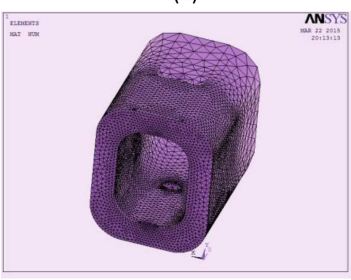

(b)

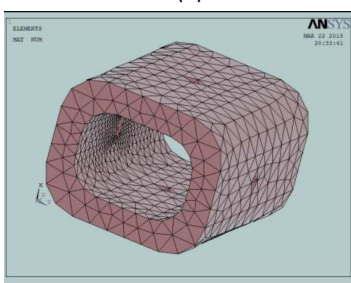

(c)

Fig. 4. FEA models: (a) wood cell without sieve plate, (b) wood cell with two sieve-plates, (c) wood cell with four sieve-plates.

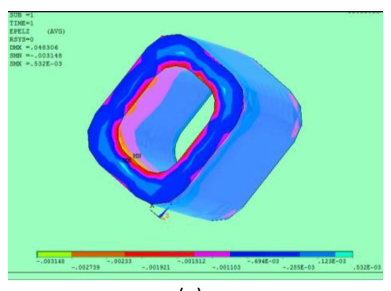

(a)

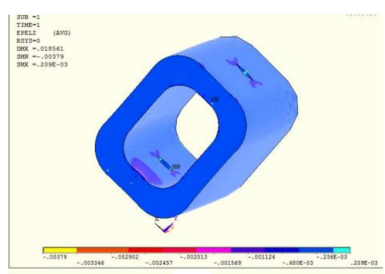

(b)

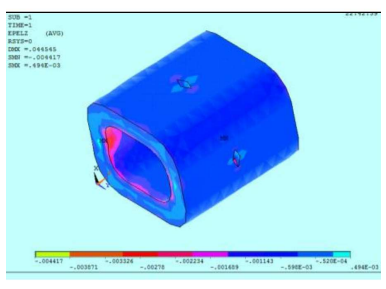

(c)

Fig. 5. FEA results for strain distributions: (a) wood cell without sieve-plate (model I), (b) wood cell with two sieve-plates (model II), (c) wood cell with four sieveplates (model III).

TABLE II

Finite element solutions of three wood cell models under compression loading.

\begin{tabular}{|c|c|c|c|c|c|c|c|c|c|}
\hline \multirow[b]{2}{*}{$\begin{array}{l}\text { Material } \\
\text { type }\end{array}$} & \multicolumn{3}{|c|}{$\begin{array}{c}\text { Equivalent wood cell model } \\
\text { without sieve-plates (model I) }\end{array}$} & \multicolumn{3}{|c|}{$\begin{array}{c}\text { Equivalent wood cell model } \\
\text { with two sieve-plates (model II) }\end{array}$} & \multicolumn{3}{|c|}{$\begin{array}{l}\text { Equivalent wood cell model } \\
\text { with four sieve-plates (model III) }\end{array}$} \\
\hline & $\begin{array}{c}\left(\varepsilon_{z}\right)_{\max } \\
\left(\varepsilon_{z}\right)_{\min } \\
{[\mu \mathrm{m} / \mu \mathrm{m}]}\end{array}$ & $\begin{array}{c}\left(\delta_{z}\right)_{\max } \\
\left(\delta_{z}\right)_{\min } \\
{[\mu \mathrm{m}]}\end{array}$ & $\begin{array}{c}\left(\sigma_{z}\right)_{\max } \\
\left(\sigma_{z}\right)_{\min } \\
{\left[\mathrm{N} / \mu \mathrm{m}^{2}\right]}\end{array}$ & $\begin{array}{c}\left(\varepsilon_{z}\right)_{\max } \\
\left(\varepsilon_{z}\right)_{\min } \\
{[\mu \mathrm{m} / \mu \mathrm{m}]}\end{array}$ & $\begin{array}{c}\left(\delta_{z}\right)_{\max } \\
\left(\delta_{z}\right)_{\min } \\
{[\mu \mathrm{m}]}\end{array}$ & $\begin{array}{c}\left(\sigma_{z}\right)_{\max } \\
\left(\sigma_{z}\right)_{\min } \\
{\left[\mathrm{N} / \mu \mathrm{m}^{2}\right]}\end{array}$ & $\begin{array}{c}\left(\varepsilon_{z}\right)_{\max } \\
\left(\varepsilon_{z}\right)_{\min } \\
{[\mu \mathrm{m} / \mu \mathrm{m}]}\end{array}$ & $\begin{array}{c}\left(\delta_{z}\right)_{\max } \\
\left(\delta_{z}\right)_{\min } \\
{[\mu \mathrm{m}]}\end{array}$ & $\begin{array}{c}\left(\sigma_{z}\right)_{\max } \\
\left(\sigma_{z}\right)_{\min } \\
{\left[\mathrm{N} / \mu \mathrm{m}^{2}\right]}\end{array}$ \\
\hline$E=0.08$ & $0.133 \times 10^{-2}$ & 0.119 & $0.187 \times 10^{-3}$ & $0.522 \times 10^{-3}$ & $0.464 \times 10^{-1}$ & $0.905 \times 10^{-4}$ & $0.123 \times 10^{-2}$ & 0.109 & $0.179 \times 10^{-3}$ \\
\hline$\nu=0.32$ & $-0.787 \times 10^{-2}$ & 0 & $-0.750 \times 10^{-3}$ & $-0.948 \times 10^{-2}$ & 0 & $-0.821 \times 10^{-3}$ & $-0.110 \times 10^{-1}$ & 0 & $-0.1958 \times 10^{-3}$ \\
\hline$\nu=0.32$ & $-0.699 \times 10^{-2}$ & 0 & $-0.750 \times 10^{-3}$ & $-0.842 \times 10^{-2}$ & 0 & $-0.821 \times 10^{-3}$ & $-0.982 \times 10^{-2}$ & 0 & $-0.958 \times 10^{-3}$ \\
\hline$E=0.1$ & $0.106 \times 10^{-2}$ & $0.95 \times 10^{-1}$ & $0.187 \times 10^{-3}$ & $0.418 \times 10^{-3}$ & $0.371 \times 10^{-1}$ & $0.905 \times 10^{-4}$ & $0.987 \times 10^{-3}$ & $0.878 \times 10^{-1}$ & $0.179 \times 10^{-3}$ \\
\hline$\nu=0.32$ & $-0.629 \times 10^{-2}$ & 0 & $-0.750 \times 10^{-3}$ & $-0.758 \times 10^{-2}$ & 0 & $-0.821 \times 10^{-3}$ & $-0.883 \times 10^{-2}$ & 0 & $-0.958 \times 10^{-3}$ \\
\hline$E=0.095$ & $0.112 \times 10^{-2}$ & $0.95 \times 10^{-1}$ & $0.187 \times 10^{-3}$ & $0.44 \times 10^{-3}$ & $0.391 \times 10^{-1}$ & $0.905 \times 10^{-4}$ & $0.104 \times 10^{-2}$ & $0.925 \times 10^{-1}$ & $0.179 \times 10^{-3}$ \\
\hline$\nu=0.32$ & $-0.663 \times 10^{-2}$ & 0 & $-0.750 \times 10^{-3}$ & $-0.798 \times 10^{-2}$ & 0 & $-0.821 \times 10^{-3}$ & $-0.929 \times 10^{-2}$ & 0 & $-0.958 \times 10^{-3}$ \\
\hline$E=0.2$ & $0.532 \times 10^{-3}$ & $0.48 \times 10^{-1}$ & $0.187 \times 10^{-3}$ & $0.209 \times 10^{-3}$ & $0.186 \times 10^{-1}$ & $0.905 \times 10^{-4}$ & $0.494 \times 10^{-3}$ & $0.439 \times 10^{-1}$ & $0.179 \times 10^{-3}$ \\
\hline$\nu=0.32$ & $-0.315 \times 10^{-2}$ & 0 & $-0.750 \times 10^{-3}$ & $-0.379 \times 10^{-2}$ & 0 & $-0.821 \times 10^{-3}$ & $-0.442 \times 10^{-2}$ & 0 & $-0.958 \times 10^{-3}$ \\
\hline
\end{tabular}

The stress and strain distributions were plotted for the model II on the defined path. The path was defined with 16 nodal coordinates along the $z$ direction (Fig. 6). As shown in Fig. 6a, the pressure loading was applied to the free surface at the nodal point number 16 and as shown in Fig. 6b, the surface at the nodal point number 1 , the displacement based boundary conditions were assumed zero. The normalized stress $\sigma / \sigma_{\max }$ and strain $\varepsilon / \varepsilon_{\max }$ distributions were plotted according to the path defined nodal points from 1 through 16, as shown in Fig. $6 \mathrm{~b}$ and c. 

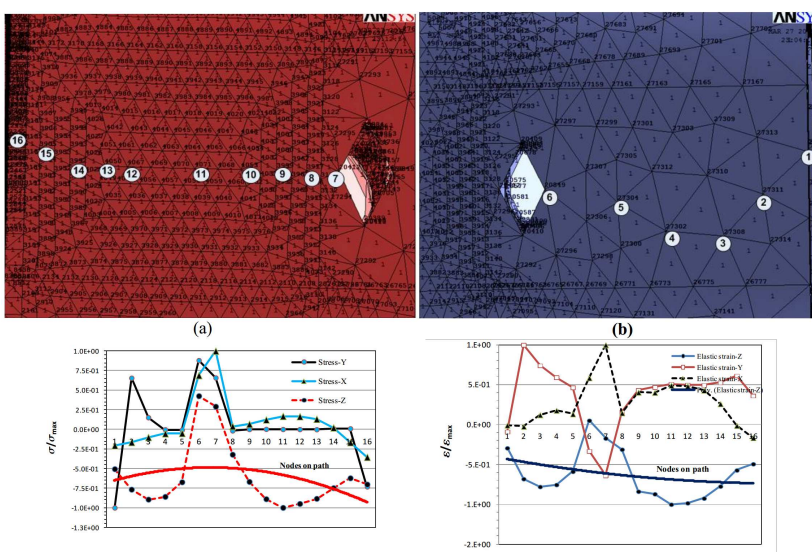

Fig. 6. Stress and strain distributions on the defined path along the $z$-axis for the model III: (a) nodal point numbers on the path along the loaded side of the cell (point number 16), (b) nodal point numbers on the path along the displacement boundary conditions applied side of the cell (point number 1), (c) normalized stress $\sigma / \sigma_{\max }$ distributions, (d) normalized strain $\varepsilon / \varepsilon_{\max }$ distributions.

\section{Results and conclusions}

The result of this study showed that the equivalent cell structure elasticity constant value reached to $E_{\text {cell }}=$ $0.08 \mathrm{~N} / \mu \mathrm{m}^{2}$ amount levels according to the two parameter dependent iterations. The most suitable elasticity constant of the equivalent cell wall reference to the literature was $80 \mathrm{GPa}$ according to our study. The obtained minimal strain values were $\varepsilon_{\max }=0.133 \times 10^{-2}$, $\varepsilon_{\max }=0.522 \times 10^{-3}$, and $\varepsilon_{\max }=0.123 \times 10^{-2}$ for the models I, II, and III, respectively. The generated maximum strain values were $\varepsilon_{\max }=0.532 \times 10^{-3}, \varepsilon_{\max }=$ $0.209 \times 10^{-3}$ and $\varepsilon_{\max }=0.494 \times 10^{-3}$ corresponding to the models I, II, and III for $E_{\text {cell }}=0.08 \mathrm{~N} / \mu \mathrm{m}^{2}$ (Table II). In the literature survey, the elastic modulus for a short wood fiber sample of spruce latewood was found as $E_{\text {cell }}=20.8-60.1 \mathrm{GPa}$ [9]. In order to confirm our results, more studies need to be performed in future.

According to our study, the most suitable model for strain and elasticity constants for the wood cell wall was model III (wood cell with four sieve-plates), which gives the nearly true value according to the literature survey. According to another important result of our study, the maximum stress and strain distributions were obtained around the sieve-plates. These are the locations denoted between the nodal numbers 6 and 7 as shown in Fig. 6c and d. Additionally, the developing stress and strain distributions through the $x$ and $y$ axes were found to be larger than the third directional stress along $z$ axis.

\section{Acknowledgments}

Thanks for the great supports of FİGES and BAP project under grant No. 06/2011-57. This study was performed in Gazi University Ankara, Turkey.

\section{References}

[1] S. Cramer, D. Kretschmann, R. Lakes, T. Schmidt, Holzforschung 59, 531 (2005).

[2] E. Günay, Y. Orçan, Turkish J. Eng. Env. Sci. 31, 89 (2007).

[3] S. T. Kaya, M.Sc. Thesis, Gazi University Graduate School of Natural and Applied Sciences, Ankara 2007.

[4] E. Roszyk, W. Moliński, E. Fabisiak, Wood Res. 58, 329 (2013).

[5] D.W. Green, J.E. Winandy, D.E. Kretschmann, www.conradfp.com/pdf/ch4-Mechanical-Propertiesof-Wood.pdf.

[6] E. Günay, H. Golmohammadi, Ş.T. Kaya, Mater. Sci. Appl. 5, 1060 (2014).

[7] H. Qing, L. Mishnaevsky, Comp. Mater. Sci. 46, 310 (2009).

[8] A.G. Facca, M.T. Kortschot, N. Yan, CompositesPart A 37, 1660 (2006).

[9] S. Wang, S.H. Lee, Q. Cheng, in: Cellulose Structure and Properties, Derivatives and Industrial Users, Eds. A. Lejeune, T. Deprez, Nova Sci. Publ. Inc., New York 2010, p. 459.

[10] B.A. Jayne, Forest Prod. J. 6, 316 (1960).

[11] Z. Zhou, Y. Zhang, S. Wang, in: Engineered Wood Products Based on Poplar Willow Wood, IPC Conf. Proc., Nanjing (China), Ed. Hua Yukun, 2008, p. 55. 